\title{
Disaster Management Problems in Indonesia: Urgency Of "Migrant Worker" Data Collection, Learning from Conditions During The Covid-19 Pandemic
}

\author{
Muhammad Arif Fahrudin Alfana, Agus Joko Pitoyo, Hidayati Nur Rohmah, Rizky \\ Laudiansyah
}

Universitas Gadjah Mada

arif.fahrudin@ugm.ac.id

\section{Article History}

accepted 31/08/2020

\begin{abstract}
The COVID-19 pandemic has opened a new view that management of our population administration has not been good. The weakness is the unavailability of migrant worker database which is very important when a disaster like this occurs. This paper explains the urgency of migration data, learning from the Covid-19 pandemic. This research is a quantitative and qualitative research. The method in this paper uses literature study and interviews with informants. Data analysis uses descriptive analysis. In conclusion, migration data play an important role when outbreaks such as COVID-19 occur. Migration data will be used as a basis for tracking population is doing internal migration. With this data, the government in the area of origin and destination can carry out various kinds of protection for the population. innovations carried out by the Population and Civil Registration Agency or other agencies in each district and city are needed to integrate this data into their systems. This internal migration data will later be used by the government as a good decision support system whenever needed.
\end{abstract}

Keywords: Covid-19, data collection, migrant worker, internal migration, disaster management

\begin{abstract}
Abstrak
Pandemi COVID-19 telah membuka beberapa kelemahan yang kaitannya dengan administrasi kependudukan. Kelemahan yang dimaksud adalah belum tersedianya database penduduk perantau yang menjadi sangat penting ketika terjadi wabah seperti ini. Tulisan ini bertujuan untuk menjelaskan urgensi data migrasi, khususnya pekerja migran ketika pandemi Covis-19 terjadi. Penelitian ini adalah penelitian kuantitatif dan kualitatif. Metode pengumpulan data dalam tulisan ini menggunakan studi kepustakaan dan wawancara kepada informan. Analisis data menggunakan analisis deskriptif. Kesimpulan yang diperoleh adalah data migrasi memegang peranan penting ketika wabah seperti COVID-19 terjadi. Data migrasi akan dijadikan sebagai dasar tracking penduduk yang sedang melakukan migrasi sehingga pemerintah daerah asal maupun tujuan dapat melakukan berbagai macam perlindungan bagi penduduk tersebut. Mengingat urgensinya sangat penting, inovasi Dukcapil atau OPD lain di masing-masing kabupaten dan kota sangat diperlukan untuk mengintegrasikan data ini ke sistemnya. Hal ini agar data migrasi dapat digunakan pemerintah sebagai decision support system yang baik ketika sewaktu-waktu diperlukan
\end{abstract}

Kata kunci: Covid-19, pendataan penduduk, perantau, migrasi internal, manajemen bencana

Social, Humanities, and Education Studies (SHEs): Conference Series

p-ISSN 2620-9284

https://jurnal.uns.ac.id/shes

e-ISSN 2620-9292 


\section{PENDAHULUAN}

Awal tahun 2020, dunia termasuk di dalamnya Indonesia mengalami kejadian bencana yang sangat dahsyat. Bencana tersebut, jika dalam Undang-undang nomor 24 tahun 2007 tentang penanggulangan bencana, termasuk ke dalam bencana nonalam yang berupa epidemi dan wabah penyakit. Bencana yang dimaksud adalah terjadinya wabah penyakit Covid-19 yang secara resmi diumumkan sebagai pandemi global oleh WHO pada awal Maret 2020 dengan tingkat bahaya yang sangat tinggi (Cucinotta and Vanelli M, 2020; Mahase, 2020; Sohrabi, et.al., 2020). Selain memiliki efek yang mematikan, ternyata pandemi ini juga menyebabkan dampak ikutan lain berupa perekonomian yang terganggu (Copenhagen Economics, 2020; Jackson, Weiss, Schwarzenberg, and Nelson, 2020). Bahkan temuan terakhir menyebutkan pandemi ini akan memicu resesi di beberapa negara di dunia (World Bank, 2020). Bahkan surat kabar daring bbc.com pada April 2020 dan Arbar (2020) menyebutkan bahwa terjadi kekhawatiran bahwa resesi yang akan terjadi karena pandemi Covid-19 menjadi resesi terburuk dibandingkan Depresi Hebat (Great Depression) tahun 1930an.

Dampak perekonomian yang memburuk dan ancaman resesi di berbagai sektor perekonomian berpengaruh secara langsung terhadap tenaga kerja, baik pekerja lakilaki dan terlebih bagi para pekerja wanita (United Nations, 2020; World Trade Organization, 2020). Pemberhentian sementara atau bahkan diputus kontraknya merupakan dampak langsung yang dimaksud. Di Indonesia, dampak pandemi ini menyebabkan banyak pabrik atau perusahaan tutup serta tenaga kerja yang dirumahkan. Sari (2020) melaporkan dampak pandemi ini di Jakarta per 14 April 2020 adalah sebanyak 1.262 perusahaan tutup dengan 177.344 pekerja yang menghentikan seluruh kegiatannya. Dampak lainnya adalah sebanyak 2.341 perusahaan dengan total 833.837 pekerja mengurangi sebagian kegiatan produksinya.

Banyaknya pekerja yang terimbas ini diduga kuat sebagiannya merupakan para perantau. Hal ini dikarenakan sekitar 22 persen pekerja di Jakarta adalah para perantau yang bekerja di berbagai sektor perekonomian (BPS, 2020). Perantau sendiri menurut kamus besar bahasa indonesia dapat didefinisikan sebagai seseorang yang mencari penghidupan di negeri/daerah lainnya. Sedangkan dalam studi demografi perantau ini dapat dideskripsikan sebagai pekerja migran. Akibat dari terdampaknya para perantau karena bencana nonalam ini maka sebagian besar kepala daerah mencoba untuk membantu. Gubernur Jawa Tengah merupakan salah satu kepala daerah yang berinisiatif untuk membantu warganya yang terdampak pandemi Covid-19 ini (Hidayati, 2020). Sayangnya data mengenai perantau ini tidak dimiliki oleh beberapa wilayah. Akibatnya bantuan bagi para perantau ini menjadi terhambat.

Salah satu kasus yang menjadi sorotan di media elektronik adalah tidak dimilikinya data perantau oleh Sekda Blora untuk membantu warganya di perantauan yang terdampak Covid 19 (Budi, 2020). Chandra (2020) memberikan informasi bahwa dari wawancara yang dilakukannya terhadap Sekda Blora diketahui bahwa Sekda Blora sendiri ingin membantu perantau dari warganya yang terkena dampak Covid-19. Akan tetapi memang diakui bahwa data perantau yang menjadi dasar kebijakan bantuan tidak dimiliki oleh pemerintah Blora. Bahkan data tersebut telah ditanyakan ke Dinas Sosial Kabupaten Blora dan hasilnya memang tidak ada data perantau tersebut. Karena tidak adanya data perantau ini bahkan Sekda Blora oleh Gubernur Jawa Tengah diminta mundur dari jabatannya (Budi, 2020). Permasalahan pendataan ini ternyata tidak hanya di Jawa Tengah saja, tetapi diduga pendataan perantau yang belum baik di beberapa daerah lain menjadi penyebab para perantau kesulitan mengakses bantuan di saat pandemi Covid-19 terjadi.

Dikaitkan dengan manajemen penanggulangan bencana, tentu hal ini sangat menarik. Pada kasus ini posisi perantau merupakan obyek yang merupakan penduduk rentan yang terdampak bencana. Dalam aspek penyelenggaraan penanggulangan 
bencana, data perantau merupakan data dasar yang dibutuhkan dalam serangkaian upaya yang meliputi penetapan kebijakan, kegiatan pencegahan, tanggap darurat hingga tahap rehabilitasi selama pandemi Covid-19 terjadi. Berdasarkan paparan tersebut, pandemi Covid-19 telah membuka beberapa kelemahan yang harus diakui dalam kaitannya dengan administrasi kependudukan dan manajemen bencana. Kelemahan yang dimaksud adalah belum tersedianya database penduduk perantau yang menjadi sangat penting ketika terjadi wabah seperti ini terjadi. Tulisan ini bertujuan untuk menjelaskan urgensi data perantau, yang secara khusus masuk dalam pembahasan migrasi internal, dimana selama pandemi Covid-19 data ini menjadi sorotan.

\section{METODE}

Penelitian ini merupakan studi pendahuluan urgensi pendataan data perantau khususnya jika dikaitkan dengan permasalahan manajemen bencana di Indonesia. Data yang digunakan adalah data sekunder dari BPS dan data pendukung dari publikasi di berbagai media. Data lain yang digunakan adalah data primer yang diperoleh melalui wawancara. Yunus (2010) membagi penelitian menjadi 3 bagian yakni berdasarkan populasi, obyek yang diteliti dan analisis. Berdasarkan populasinya, penelitian ini termasuk studi kasus. Berdasarkan obyeknya merupakan survei, dan terkait analisis merupakan penelitian kuantitatif dan kualitatif. Gambaran metode penelitian ini secara visual dapat dilihat dalam Gambar 1 sebagai berikut.

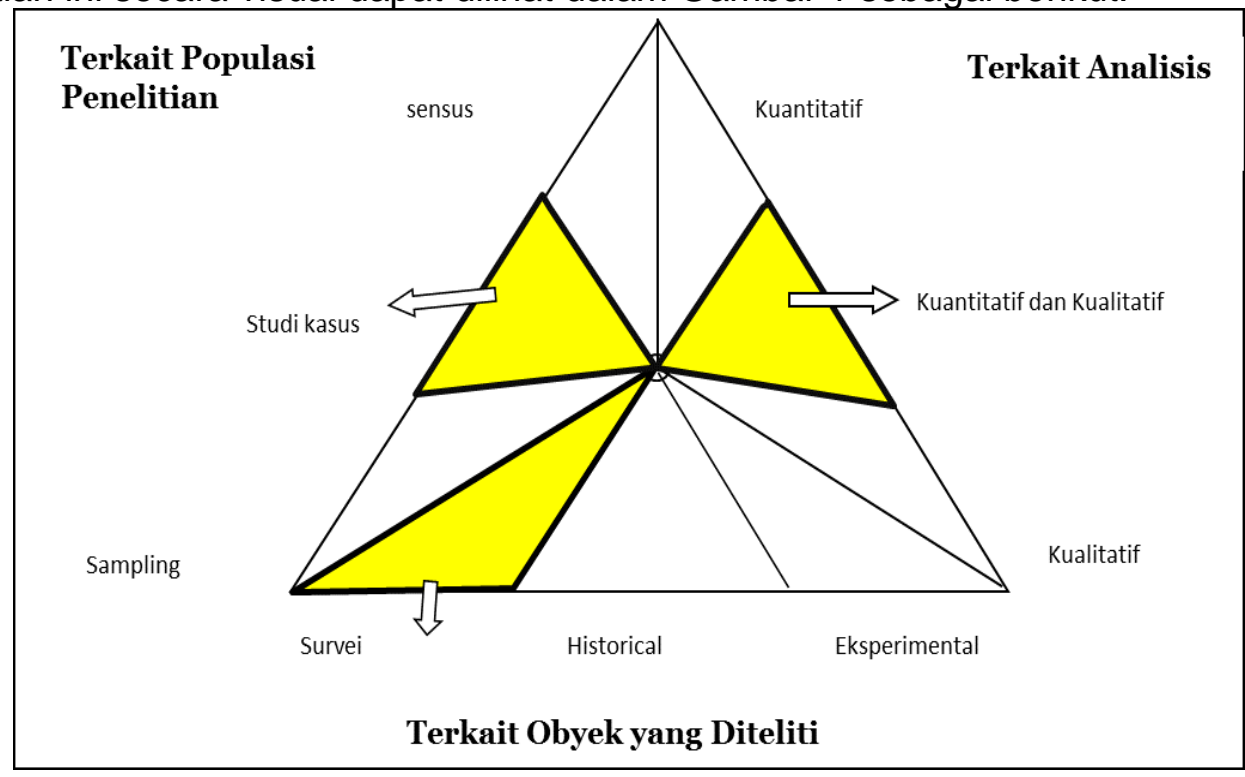

Gambar 1. Metode Penelitian Permasalahan Manajemen Bencana Di Indonesia: Urgensi Pendataan Para Perantau, Belajar Dari Kondisi Selama Pandemi Covid-19

Metode pengumpulan data sekunder dilakukan dengan menggunakan metode studi literatur/kepustakaan. Data ini dianalisis dengan deskriptif kuantitatif. Data tersebut bersumber dari publikasi BPS (2020) berjudul Analisis Mobilitas Tenaga Kerja Hasil Sakernas 2018. Data yang digunakan adalah data jumlah perantau. Jumlah perantau ini teridentifikasi dari data publikasi berupa:

1. Jumlah pekerja migran sirkuler

2. Jumlah pekerja komuter, dan

3. Jumlah pekerja migran risen.

Ketiga kategori pekerja migran tersebut sekaligus menjadi batasan operasional obyek yang diteliti pada tulisan ini. Sebagai pendukung informasi, pengambilan data primer dilakukan melalui wawancara dilakukan kepada narasumber/informan. 


\section{HASIL DAN PEMBAHASAN}

Pembahasan pertama adalah tentang jumlah perantau dan distribusinya di Indonesia. Salah satu definisi dari perantau menurut Kamus Besar Bahasa Indonesia adalah orang yang mencari penghidupan di negeri/daerah lainnya. Menurut Badan Pusat Statistik (2020), definisi ini dapat diakomodir dalam pengertian angkatan kerja yang kegiatan utamanya adalah bekerja dan berada di daerah yang bukan daerah asalnya. Gambar 1 merupakan konsep perantau yang dapat dikatakan diakomodir oleh BPS dan menjadi batasan operasional dalam penelitian ini. Dalam gambar tersebut, perantau yang bekerja memiliki definisi operasional sebagai penduduk usia 15 tahun ke atas yang bekerja lintas area, dan terbagi menjadi tiga bagian. Ketiga bagian tersebut adalah pekerja komuter, pekerja sirkuler dan pekerja migrasi risen.

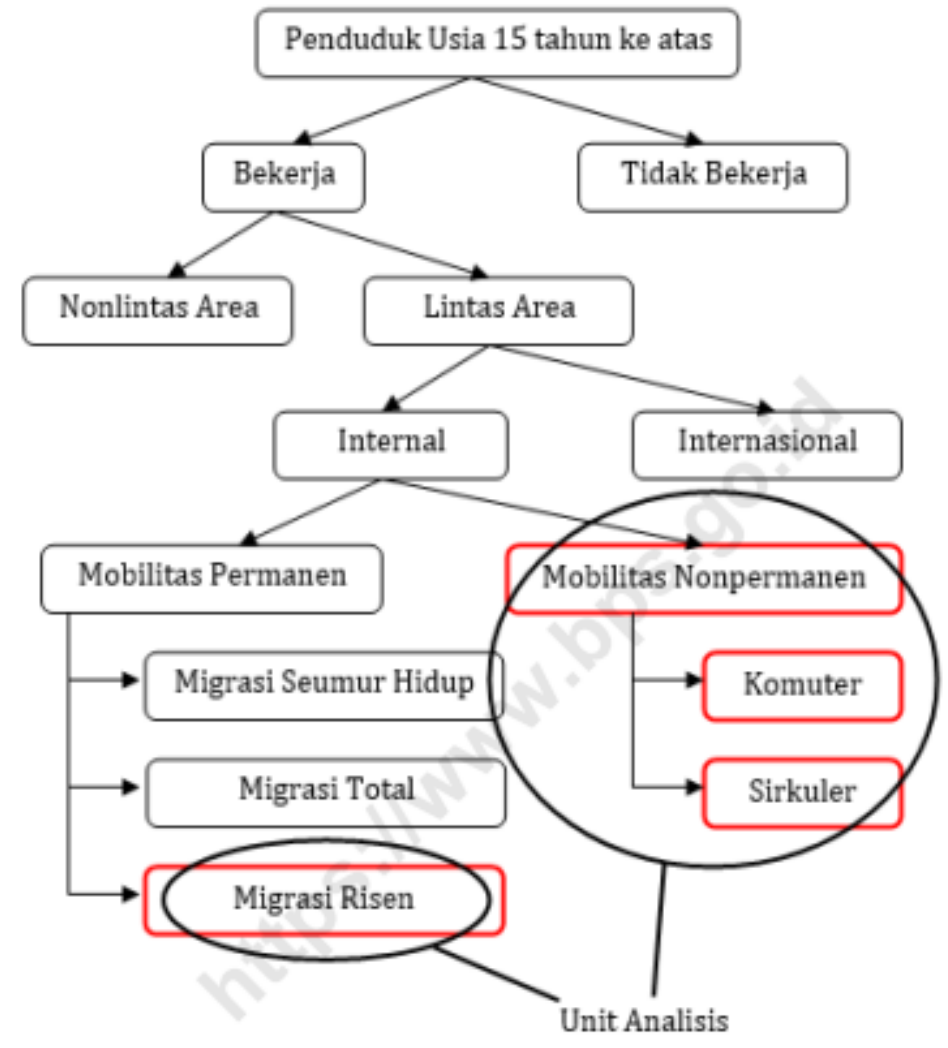

Gambar 2. Konsep Perantau yang Bekerja Menurut BPS Sumber: Disalin dari BPS, 2020 (hal.28)

Badan Pusat Statistik mendefinisikan ketiganya dengan lengkap. Pekerja komuter didefinisikan sebagai pelaku mobilitas ulang alik dengan tujuan utama untuk bekerja. Untuk pekerja sirkuler adalah pelaku mobilitas sirkuler dengan tujuan utama untuk bekerja. Sedangkan pekerja migrasi risen adalah pelaku mobilitas yang tujuan utamanya adalah bekerja dengan kondisi tempat tinggal lima tahun yang lalu berbeda dengan sekarang.

Berdasarkan batasan tersebut, jumlah perantau di Indonesia jumlahnya sebanyak 16,3 juta jiwa (BPS, 2020). Jumlah tersebut kira-kira sekitar separuh jumlah penduduk Jawa Tengah atau 4-5 kali lipat seluruh penduduk DI Yogyakarta menurut Sensus 2010. Jika dilihat sebarannya, distribusi perantau tersebar di seluruh wilayah Indonesia. Dari data BPS (2020) dapat diketahui berapa sebaran perantau dilihat dari sisi migrasi risen, serta dari sisi movers (jumlah perantau dari hasil penjumlahan pekerja komuter dan sirkuler). Gambar 2 merupakan persentase sebaran perantau di 
Indonesia. Berdasarkan gambar tersebut diketahui bahwa sebaran perantau terbesar berada di Pulau Jawa. Berdasarkan provinsinya, perantau terbanyak dari sisi pekerja komuter dan sirkuler berada di Provinsi DKI Jakarta (22,9 persen). Sedangkan perantau dari migrasi risen terbanyak ada di Jawa Barat (16,5 persen).

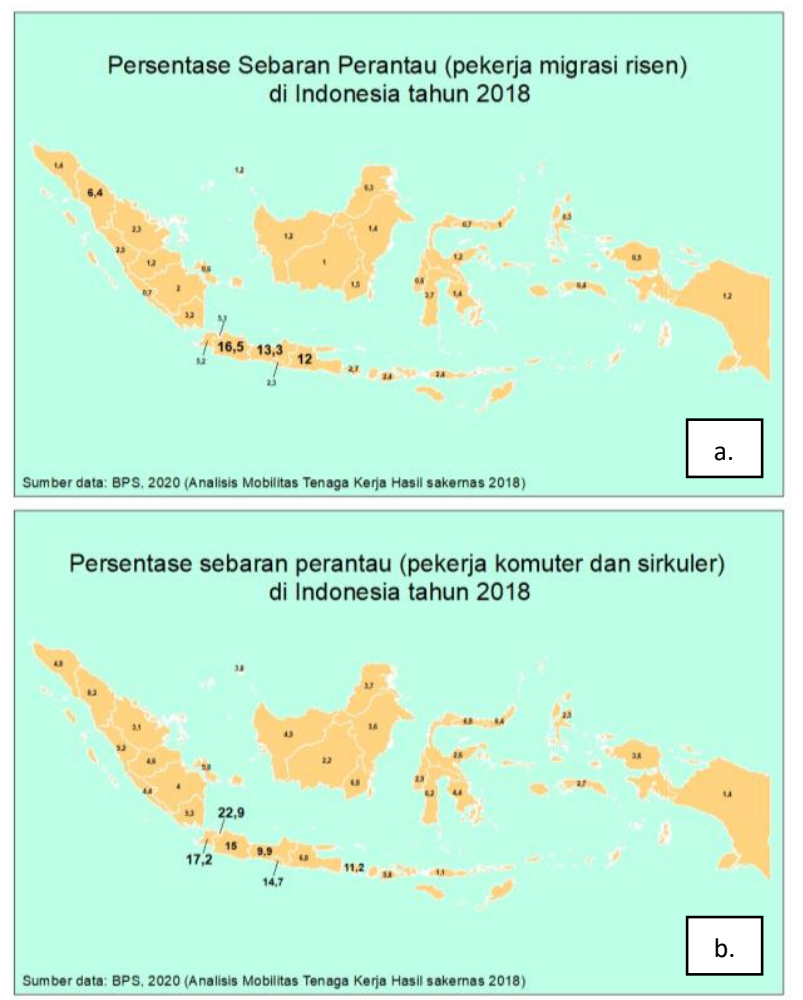

Gambar 2. Distribusi Perantau di Indonesia Berdasarkan Kategori Pekerja Migran Risen (a.) dan Pekerja Movers/Pekerja Komuter dan Sirkuler (b.)

Sumber: BPS, 2020

Pembahasan kedua adalah tentang urgensi pendataan para perantau atau pekerja migran. Pada Januari 2020, pemerintah telah menerbitkan Peraturan Pemerintah (PP) 10 tahun 2020 tentang Tata Cara Penempatan Pekerja Migran Indonesia oleh Badan Pelindungan Pekerja Migran Indonesia (BP2PMI). Di dalam PP tersebut tertuang aturan mengenai pendataan pekerja migran Indonesia yang bekerja di Luar Negeri. Bahkan dalam aturan tersebut dimuat bahwa pendataan difasilitasi negara sampai dengan penggunaan teknologi pendataan sidik jari biometrik. Hal ini merupakan langkah besar pendataan para perantau di Indonesia. Hasilnya dari data BP2PMI diketahui data secara pasti bahwa per April 2020 jumlah penempatan pekerja migran Indonesia di Luar Negeri sebanyak 2.347 jiwa. Sayangnya pendataan semacam ini tidak dilakukan pada para perantau yang bekerja di dalam negeri. Padahal secara jumlah, perantau di dalam negeri jumlahnya berkali-kali lipat dari perantau di luar negeri. Pandemi Covid-19 yang terjadi seharusnya menjadi pembelajaran bahwa ternyata pendataan perantau yang merupakan pekerja migran di dalam negeri juga perlu dilakukan.

Pandemi Covid-19 yang terjadi pada 2020 memberikan gambaran bagaimana para perantau merupakan penduduk rentan yang sangat terdampak dari musibah ini. Terlepas dari apakah perantau tersebut merupakan pekerja migran di dalam negeri atau di luar negeri, semestinya pemerintah melindungi kelompok ini. Para perantau sangat membutuhkan bantuan karena sebagian dari mereka ada yang dirumahkan sehingga kehidupan mereka terancam. Oleh sebab itu dapat dibayangkan bagaimana 
jika data perantau ini tidak tersedia. Bisa dipastikan penetapan kebijakan, kegiatan pencegahan, tanggap darurat hingga tahap rehabilitasi selama pandemi Covid-19 terjadi tidak dapat dilakukan secara maksimal.

Beberapa laporan menjelaskan bagaimana urgensi pendataan warga terdampak, termasuk di dalamnya perantau ini, sangat penting jika dikaitkan dengan manajemen bencana. Vitorio (2020) menulis bahwa setengah ton telur bantuan untuk korban bencana Covid-19 di Kota Depok Jawa Barat membusuk dan terpaksa dimusnahkan. Hal ini dikarenakan telur tersebut tersebut tidak tersalurkan karena ketidakcocokan data dengan kondisi lapangan. Chafda (2020) dan Budi (2020) juga melaporkan bahwa salah satu kabupaten di Jawa Tengah tidak memiliki data perantau. Akibatnya pemerintah provinsi sempat kesulitan untuk melaksanakan tindak lanjut pemberian bantuan bagi mereka. Dzulfaroh (2020) dalam laporannya menyatakan meskipun awalnya telah ditutup pada April 2020, program bantuan bagi perantau Jawa Tengah di Jabodetabek tetap dibuka sampai Juni 2020. Hal ini untuk mengantisipasi jika ada warga yang belum terdata. Laporan dari Dzulfaroh (2020) ini mengindikasikan bahwa Provinsi Jawa Tengah yang menjadi salah satu penyumbang jumlah perantau di Indonesia tidak benar-benar memiliki data up to date tentang jumlah perantau yang berasal dari wilayahnya. Hal ini sekaligus menimbulkan dugaan lain bahwa provinsi lain juga sebenarnya mengalami masalah serupa.

Belajar dari pandemi Covid-19, hal ini seharusnya digunakan untuk peningkatan kualitas pendataan perantau di Indonesia. Pandemi Covid-19 telah memberikan pelajaran bahwa data migrasi memegang peranan penting dalam manajemen bencana di Indonesia. Dari sini pula data migrasi, dalam kasus ini adalah perantau, akan dijadikan sebagai dasar tracking berapa besar penduduk yang sedang melakukan migrasi sehingga pemerintah daerah asal maupun tujuan dapat melakukan berbagai macam perlindungan bagi penduduk tersebut. Data migrasi ini sangat krusial sebagai data dasar penetapan kebijakan, kegiatan pencegahan, tanggap darurat hingga tahap rehabilitasi selama pandemi Covid-19.

Ke depan, mengingat urgensinya sangat penting, inovasi Dukcapil atau OPD lain di masing-masing kabupaten dan kota sangat diperlukan untuk mengintegrasikan data ini ke sistemnya. Inovasi juga dapat dilakukan di level lain misalnya dari level desa sampai ke level pusat. Hal ini agar data migrasi, khususnya yang terkait dengan perantau dapat digunakan pemerintah sebagai decision support system yang baik ketika sewaktu-waktu diperlukan. Salah satu inovasi yang dapat dilakukan di level desa misalnya melakukan pendataan migran dengan membangun software tertentu. Sukamdi, salah satu ahli migrasi di Pusat Studi Kependudukan dan Kebijakan UGM menyatakan:

"Salah satu kebijakan preventif dan kuratif dari sisi demografi terkait Pandemi Covid-19 ini adalah melakukan pengembangan sistem data migrasi di tingkat Desa. Hal ini akan sangat penting jika berhasil dilakukan karena identifikasi dini bisa dilakukan sebagai basis pengembangan pencegahan.Dengan bagusnya data migrasi ini maka kita akan tahu siapa saja migran di daerahnya, sehingga kebijakan dapat diambil dua arah, baik di daerah asal maupun di daerah tujuan. Bagaimana caranya? Caranya adalah tidak harus merubah total atau membuat dari awal. Sistem yang sudah ada sebagai embrio kemudian dikembangkan dan disempurnakan".

\section{SIMPULAN}

Dalam kajian ini, beberapa kesimpulan yang dapat diambil diantaranya:

1. Jumlah perantau di Indonesia menurut BPS (2020) diperkirakan sebesar 16,3 juta jiwa yang berasal dari pekerja migran risen, pekerja komuter dan pekerja 
sirkuler. Jumlahnya akan semakin besar jika ditambah dari perantau dari pekerja migran seumur hidup dan migrasi total.

2. Data migrasi, dalam hal ini perantau, memegang peranan penting ketika wabah seperti COVID-19 terjadi.

3. Data migrasi, dalam kasus ini adalah perantau, akan dijadikan sebagai dasar tracking berapa besar penduduk yang sedang melakukan migrasi sehingga pemerintah daerah asal maupun tujuan dapat melakukan berbagai macam perlindungan bagi penduduk tersebut.

4. Ke depan, mengingat urgensinya sangat penting, inovasi Dukcapil atau OPD lain di masing-masing kabupaten dan kota sangat diperlukan untuk mengintegrasikan data ini ke sistemnya. Hal ini agar data migrasi, khususnya yang terkait dengan perantau dapat digunakan pemerintah sebagai decision support system yang baik ketika sewaktu-waktu diperlukan.

5. Penelitian pendahuluan ini juga membuka peluang bagi penelitian berikutnya baik terkait urgensi pendataan perantau, atau secara lebih luas yakni pendataan para migran secara umum. Hal ini dikarenakan urgensi data ini sangat besar dan pembelajaran pentingnya data migrasi ini ketika Covid-19 menjadi contoh yang sangat bermanfaat.

\section{DAFTAR PUSTAKA}

Arbar, T. F. (2020). Mengenal Great Depression, Krisis Malaise yang Ditakutkan IMF. cnbcindonesia.com. Diakses dari https://www.cnbcindonesia.com/news/ 20200416130755-4-152381/mengenal-great-depression-krisis-malaise-yangditakutkan-imf

Badan Pusat Statistik. (2020). Analisis Mobilitas Tenaga Kerja Hasil Sakernas 2018. Jakarta: Badan Pusat Statistik. ISSN: 2598-5663

bbc.com. (2020). Coronavirus: World economy 'may face double recession'. bbc.com. Diakses dari https://www.bbc.com/news/business-52306001

BP2MI. (2020). Data Penempatan dan Pelindungan PMI Periode April 2020. Jakarta Selatan: Badan Perlindungan Pekerja Migran Indonesia. Data dapat diakses di https://bp2mi.go.id/uploads/statistik/images/data_26-052020_Laporan_Pengolahan_Data_BNP2TKI_APRIL_fix.pdf

Budi, T. (2020). Diminta Ganjar Mundur, Sekda Blora Akui Tak Miliki Data Perantau. news.okezone.com. Diakses dari https://news.okezone.com/read/ 2020/05/10/512/2211686/diminta-ganjar-mundur-sekda-blora-akui-tak-miliki-dataperantau

Chandra, F. (2020). Diminta Ganjar Mundur, Sekda Blora Berdalih Sulit Data Warga di Perantauan. news.detik.com. Diakses dari https://news.detik.com/berita-jawatengah/d-5008549/diminta-ganjar-mundur-sekda-blora-berdalih-sulit-data-wargadi-perantauan

Copenhagen Economics. (2020). Economic Consequences Of The Covid-19 Pandemic. March 2020. Copenhagen Economics. https://www.copenhageneconomics.com/dyn/resources/Publication/publicationPD F/0/530/1585835646/copenhagen-economicseconomic-consequences-covid19. pdf.

Cucinotta, D and Vanelli, M. (2020). WHO Declares COVID-19 a Pandemic. Acta Biomed. 2020 Mar 19;91(1):157-160. doi: 10.23750/abm.v91i1.9397.

Hidayati, N. (2020). Data Perantau Jateng di Jakarta, Ganjar Pastikan Mereka Dapat Bantuan. portaljember.pikiran-rakyat.com. Diakses dari https://portaljember. pikiran-rakyat.com/regional/ pr-16365492/data-perantau-jateng-di-jakarta-ganjarpastikan-mereka-dapat-bantuan 
Jackson, J.K., Weiss, M.A., Schwarzenberg, A.B. and Nelson, R.M. (2020). Global Economic Effects of COVID-19. Congressional Research Service. https://crsreports.congress.gov. R46270.

Mahase E. (2020). Covid-19: WHO declares pandemic because of "alarming levels" of spread, severity, and inaction. BMJ. 2020 Mar 12;368:m1036. doi: 10.1136/bmj.m1036.

Perantau (Def. 1) (n.d). Dalam Kamus Besar Bahasa Indonesia (KBBI) Online. Diakses melalui https://kbbi.web.id/rantau, 18 Agustus 2020.

Sari, N. (2020). PSBB di Jakarta, 1.262 Perusahaan Tutup, 2.341 Lainnya Kurangi Kegiatan. Megapolitan.kompas.com. Diterbitkan pada 14.53 tanggal 14/04/2020. Diakses dari https://megapolitan.kompas.com/read/2020/04/14/14534231/psbbdi-jakarta-1262-perusahaan-tutup-2341-lainnya-kurangi-kegiatan

Sekretariat Negara Republik Indonesia. (2020). Jakarta: Sekretariat Negara Republik Indonesia

Sohrabi, C., Alsafi, Z., O'Neill, N., Khan, M., Kerwan, A. Al-jabir, A., Losifidis, C., and Agha, R. (2020).World Health Organization declares global emergency: A review of the 2019 novel coronavirus (COVID-19). International Journal of Surgery. Volume 76, April 2020, Pages 71-76 https://doi.org/10.1016/j.ijsu.2020.02.034

United Nations. (2020). Policy Brief: The World of Work and COVID-19. United Nations. https://unsdg.un.org/sites/default/files/2020-07/policy-briefthe _world_of_work_and_covid-19.pdf

Vitorio, $\bar{M}$. (2020). Setengah Ton Telur Bansos Pemprov Jabar untuk Warga Depok Membusuk, Ini Penjelasannya. megapolitan.kompas.com. Diakses melalui https://megapolitan.kompas.com/read/2020/06/29/17262051/setengah-ton-telurbansos-pemprov-jabar-untuk-warga-depok-membusuk-ini.

World Bank. (2020). The Economy in the Time of Covid-19. LAC Semiannual Report. April 2020. Washington, DC: World Bank. World Bank. https://openknowledge.worldbank.org/handle/10986/33555 License: CC BY 3.0 IGO.

World Trade Organizationn. (2020). The Economic Impact Of Covid-19 On Women In Vulnerable Sectors And Economies. World Trade Organization. https://www.wto.org/english/news_e/news20_e/info_note_covid_05aug20_e.pdf 